\title{
An Analysis of Major Non-traditional Security Threats Currently Faced in Xinjiang

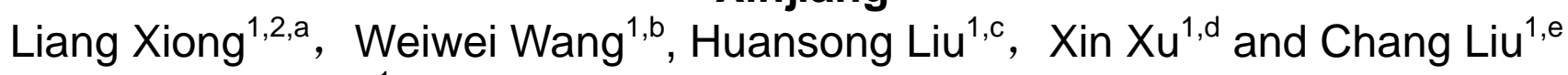 \\ ${ }^{1}$ Military Ecomomic Academy, Wuhan 430035, China \\ ${ }^{2}$ Social Science Academy of Xinjiang, Urumqi 830001,China \\ amilitaryxl@163.com, ${ }^{b} 35582368 @ q q . c o m,{ }^{c}$ liuhuansong@x263.net, ${ }^{d} x u x i n @ 163 . c o m,{ }^{e}$ liuchang7j@vi p.qq.com
}

Keyword: Non-traditional Security, Xinjiang, Security Threats

\begin{abstract}
Due to the influence of such factors as the special geographical and complicated social humanistic environment, sharp problems left over by history and vast cross-border ethnic minority areas, Xinjiang has been hot spot areas for non-traditional security problems, faced with a variety of non-traditional security threats.At present, the non-traditional security threats in Xinjiang have shifted from accidental to intensive issues, intertwined with national, religious problems and a variety of social problems, and comprehensively reflected in all aspects such as social security, economy, environment, culture and neighboring security.Systematically combing and analyzing the major non-traditional security threats currently faced in Xinjiang has become the groundwork for doing a good job to prevent and deal with the non-traditional security threats in Xinjiang.

Xinjiang is the provincial-level district of the largest land area in our country, and as one of the important strategic direction of the country, the security and stability in Xinjiang affect not only the region's economic and social comprehensive development but also the overall situation of the country.Since ancient times as an old saying goes: "Xinjiang is the barrier of Qin state, and the hedge of Yan and Jin state", "Paying attention to Xinjiang can be on garrison duty of the capital of the country, and the north and the west is linked together, forming the integrity, no weakness to take advantage of the enemy.Conversely, Xinjiang is not solid, then there is no peaceful day in Shaanxi, Gansu and Shanxi ".The security and stability of Xinjiang is very important for both the northwest and the whole country.

At present, the non-traditional security threats in Xinjiang have shifted from accidental to intensive issues, intertwined with national, religious problems and a variety of social problems, and comprehensively reflected in all aspects such as social security, economy, environment, culture and neighboring security.Thoroughly arranging the major non-traditional security threats currently faced in Xinjiang has become the groundwork for doing a good job to prevent and deal with the non-traditional security threatsin in Xinjiang.
\end{abstract}

\section{Social Security Grounds}

In terms of the actual state and influence degree of the non-traditional security issues faced in the Xinjiang region, the non-traditional security threats on the social security grounds is the biggest of all.Mainly embodied in three aspects including"East Turkistan" separatist destroy, the "three forces" interweave and mass disturbances.

\section{1 "East Turkistan" separatist and disruptive activities escalating}

With the implementation of the national western development strategy, great progress and development have been made in all fields in xinjiang, people's living standards improved significantly.But the "East Turkistan" terrorist forces desiring to see Xinjiang plunged into chaos, with the support of the United States and other western hostile forces,"East Turkistan" terrorist forces engaged in terrorist activities for long time aimed at splitting the motherland, become the cancer of 
stability and development in xinjiang, pose a real threat to frontier ethnic unity and the stability and development.

Currently, "East Turkistan"terrorist forces active frequently, terrorist incident takes on the feature of violence-oriented and openness.Influenced by the international situation, especially the influence of the situation in the Middle East and Central Asia, under the implicit backing of western hostile forces, "East Turkistan" terrorist organization in order to improve its international influence bringing Xinjiang issue to international arena and following the so-called "color revolution", have made a series of violent terrorist event, one of the biggest impact being in 2009 in Urumqi, "7.5" incident, lead to a large number of foreign withdrawal and large domestic enterprise capital flight, tourism and service industry were basically paralysed, people in panic and no mood to work, originally the pace of the rapid economic development in Xinjiang was instantly blocking, pullback.In 2011 and 2012, terrorists created terrorist violence incidences of Hetian "7.18", Kashgar "7.30" and "7.31 " and Karghalik "2.28 ", they flagrantly smash, rob and burn to the innocent people in broad daylight, terrorist violent activities being in escalation.To increase their leverage, since 2013 the "East Turkistan" terrorist activities spread from inner Xinjiang to Xinjiang outside, damage synchronously and select to implement in sensitive events and venues.In 2013, On October 28, "East Turkistan" attacked at Beijing Tiananmen Square, in less than six months the terrorist forces in Kunming carefully planning and organizing the "3.01" serious violence.These are serious threats to Xinjiang region's and even to the nation's security and social stability.

\subsection{The "Three Forces" Complicatedly Interweaved}

With the international community and China's blow to terrorism and violent terrorist activities in the new century, the three evil forces, the religious extremism, national secessionism and violence terrorism, are complicatedly intertwined, and the separatist and disruptive activities to Xinjiang are no longer limited to the violent terrorist activities but strengthen to the infiltration of the ideological field, through national, religious and human rights issues to achieve the purpose of division.Especially they implement the so-called "children project", "mother action" to instill the division thought to the school and parents, shocking by the sight.And the means and way to commit a crime tend to be more intelligent and modernization, and the criminals' cultural level has improved significantly.They clearly put forward to the direction of the "better educated, younger in age, militarized and internationalization", and announced that "they must compete for a man of knowledge, necessary to expand the power in the colleges and universities."After "9.11" incident, for example, Kashi Normal University has a student openly clamoring that "Ben Laden dare to declare war on the United States, we have nothing to be afraid of, not far from out of the Han Chinese in Xinjiang."In the "Three Forces", the ethnic separatist force seek separation is the evil political purpose they want to achieve; the religious extremism force seek religious extremist activities is the cover and banner they play to come to the reactionary political purposes; and the violent terrorism is the means they make sure to achieve the sinister political purpose.The essence of the "Three Forces " is fighting against the socialist system led by the communist party of China, destroying the great unity among people of all ethnic groups, and ultimately achieving the purpose of spliting the motherland.The "Three Forces" are complexly interweaved, not only seriously polluting the atmosphere of "stability and unity" in Xinjiang, and also severely impairing the the social stability in Xinjiang and the life and property of people of all ethnic groups.As Mr Wang Yizhou puts it, "the major threat faced by the frontier region of northwest China is the so-called 'three evil forces', which reflect the direction to consider the non-traditional security issues under the condition of regional autonomy of minority nationalities......", the recent "migration jihad " is even more reflected this.

\subsection{The Repeated Occurring of Group Events}

Samuel Huntington pointed out : "modernity establish stability, but modernization breeds instability."As same as other Chinese provinces, Xinjiang region is experiencing the "dual-track" transformation of economy and society, due to the invidious interests distribution mechanism and the 
unreasonable social system arrangement caused the large gap between rich and poor and social class solidification, the local mass incidents increasingly become a very important problem affecting the social and economic development of the country, become a huge hotbed generating social insecurity element, which produce many negative effects to the social integration and solidarity and its outbreak presents a rapidly rising trend.Every year, there are three hundred to five hundred or so of all types of mass disturbances in Xinjiang, where has become a frequency-occurring district of high incidence of mass disturbances in China, presenting such outstanding characteristics as longevity of existence, special complexity, nationality of contradiction, comprehensive nature of problems, internationality of impact, sensibility of activation, and nature of enormous hazardous and easy to influence.

\section{Economic Security Grounds}

The economic grounds of non-traditional security threats comes in a variety of forms, to analyze from the angle of region situation of Xinjiang, the relatively lagging economic development, energy security and agricultural safety issues are currently largest impact and most widespread, which will produce great negative effects to Xinjiang regional security and national security, especially in the chain reaction and the ripple effect of these problems with the "nationalization", the "politicization", and the "internationalization", therefore, the following three issues in the field of economic security should currently be focused.

\subsection{Relatively Lagging Economic Ddevelopment}

Due to historical and natural reasons, there are larger gap of the economic development between Xinjiang region and the mainland especially the coastal developed areas.And some ethnic minorities have more references on think of their own development, especially the cross-border ethnic groups, they are not only good at comparing them with the country's other ethnic groups, especially the dominant ethnic groups and also easy to contrast them with the same people on the other side of the border, and any gap is likely to trigger the national sentiment.It is observed that such the general social problems to the mainland as unbalanced economic development and poverty will be used by domestic and overseas dissidents, and be "nationalized", politicized and internationalizd, so as to promote the national division.Relatively lagging economic development is not terrible, what terrible is the bad chain reaction caused by the economic lag.As result, from the point of view of non-traditional security, the relative lag of economic development has a strong "negative orientation" effect to Xinjiang's stability, unity and prosperity.

\subsection{The Emerging Energy Security Threat}

Jin-xiang Wang, former deputy director of the National Development and Reform Commission (NDRC), deputy director of the Western Development Office of the State Council, once put it "Xinjiang in the west don't be replaced in five aspects", one of which is to say the energy.It can be said that the energy security is the important area of economic security in Xinjiang.At the same time, the energy security issues in Xinjiang region are also related to global energy security in China.Although energy types and reserves explored in Xinjiang are very considerable, but its sustained development in the future is insufficient, on the one hand, the complex geological structure in Xinjiang and the high development cost have left a large number of "low grade oil fields" in Xinjiang; On the other hand, the unreasonable price system has a strong impact on the economic development in Xinjiang as well as to have a definite negative impact on the energy security even stability and development across Xinjiang.At the same time, Xinjiang is adjacent to Central Asia where is the center of the global energy resources geopolitical landscape, especially rich in resources and with great potentiality, and will become the important hub of China's imports of oil and gas in the future.And Central Asia region is a vital point where the big countries compete with a variety of political forces, also is the area the conflict is highlighted.The security issues in this region will have a positive relationship with our energy security to large extent, which increase the threat coefficient of the regional energy security in 
Xinjiang.

\subsection{Agriculture Security Worsening}

Compared with other provinces, the agriculture security has more special effects to Xinjiang.The present and future of agricultural security in Xinjiang is related to the the people's livelihood issues in Xinjiang, also relates to the overall situation of the agriculture security in the frontier region or even in the the entire nation.On the one hand, Xinjiang is the nation's largest reserve cultivated land resources region, where, only in terms of food production, is most likely to become China's strategic replacement area of food security.Some experts even believe that "food production problems in Xinjiang could revitalize the security dilemma of the whole country".And at the same time, Xinjiang has been facing water shortage, which accelerates land desertification, where irrigation water shortage causes serious abandoned cultivation phenomenon and the agricultural production has received certain restriction. The double weakening of the capacitation and throughput of agricultural crops in Xinjiang region, as it were, makes the agricultural security increasingly worsening.

\section{Environmental Security Grounds}

Xinjiang, an undeveloped inland province in economy, is located in the arid desert area with little rainfall, dry climate, scarce forest vegetation, frequent sandstorm, and fragile ecological environment, combined with extensive backward way of resources exploitation and relatively lagging environment management measures, which results in the rigorous situation of non-traditional security threats on the level of environment security in Xinjiang, ecological environment degradation, frequent natural disasters.

\subsection{Ecological Environment Degeneration}

Xinjiang is located in the inland arid areas, the terrain of which is characterized by "three mountains holding two basins", this natural geographical characteristics objectively determines the overall the fragility of ecological environment in Xinjiang.Serious land desertization,Soil salinization in wide region and large area,Shrunk lakes and shorten rivers, exacerbated water loss and soil erosion, worsening environmental pollution, grassland deterioration, wildlife life condition destroyed, population quantity reduced, strengthening resource developmen, all these bring new damage to the already fragile ecological environment in Xinjiang.For example, the aggravate adverse phenomenon of "desertification, salinization, degeneration and alkalization" are presented in Bayingolin region -"increasingly desertification on the downstream of Tarim River, evergrowing salinization in the Beston Lake, growing degeneration on the Bayanbulak Grassland, and ever alkalization in Yanqi Basin".

\subsection{Frequent Natural Disasters}

With the complex terrain conditions, the dry climate and the special geological structure, Xinjiang has always been the place prone to natural disasters in China.Xinjiang region frequent natural disasters is mainly embodied in the variety of disaster type and the high frequency of disaster occuring.In this region, the main types of natural disasters include earthquakes, snow disasters, flood, drought, wind sand disaster and more.According to the Yaxin net(news.iyaxin.com), only in the first half of 2014, a variety of disasters had occurred in succession, such as the earthquake, low temperature, frost and snow disaster, strong wind and dust, floods and landslides, and other disasters.

\section{Culture Security Grounds}

Since ancient times, Xinjiang is a place where a variety of culture is converged, interacted and merged.The non-traditional security threats in Xinjiang region faced in the culture security grounds is both endogenous and exogenous, often accompanied by other problems, and show a strong complexity and comprehensive.To be specific, it mainly reflected in such areas as heterogeneity of national culture, the infiltration of foreign culture and the loss of traditional culture, etc. 


\subsection{Heterogeneity of National Culture}

Each multi-ethnic-populated people in Xinjiang have their own traditional culture, reflecting the different cultural characteristics.Due to the different language, manners and custom, religious faith, and national mentality and national psychology and behavior formed under the influence of long traditional culture, the national relationship of different ethnic groups formed in the process of interaction will form tension and even conflict varying degrees and different types.The cultural variation and barriers between peoples result in cultural misunderstandings and even conflicts, bringing some unstable factors to Xinjiang's national unity and social stability.The national cultural heterogeneity problem is a common problem troubling all multi-ethnic country in the world.Many practice has proved that if we make a good job of itnational culture identity problem, the different people can live in harmony, unity and progress; If play their cards badly, it will certainly become the fuze leading to social instability, ethnic conflict, even national turmoil and division.

\subsection{Foreign Cultural Penetration}

The foreign cultural penetration in Xinjiang region is many-sided, multi-realm and multi-means.These penetration activities are often are intertwined with national and religious issues , showing greater invisibility and complexity.One is the penetration taking advantage of the religion propaganda.In Xinjiang region, the hostile forces abroad are savage to utilise Islamism conducting penetration activity.For example, the religion organizations such as Saudi Arabia and other countries have provided more than three million dollars to construct 3000 Muslim mosque in Xinjiang, and take advantage of religious places operate reactionary propaganda in daylight.The second is the penetration taking advantage of the media propaganda.At present in the periphery of Xinjiang there are 8 major stations such as "Voice of America", "BBC" "Radio Free Asia", propagating to Xinjiang with 128 frequency,in Uygur, Han, Uzbekistan languages, the most contributor of which are the ethnic separatists, the propagation and penetration of disruptive public opinion is in serious condition.In addition, the hostile forces abroad also are escalating their efforts to use traditional media and new media, covering wide audience and more devastating.By right of the culture hegemony and taking advantage of the religion, people and human rights issues, The western countries noise the theory such as "culture conflict theory", "democracy and comments", "history end theory", which form the serious challenge to our national and including Xinjiang's political system reform and democratic political construction, becoming the main threat to the culture security faced in Xinjiang region.

\subsection{Traditional Culture Deletion}

The Chinese civilization has a long history, and Xinjiang regional culture blossom in radiant splendor.But in a pluralistic society of values in these time, one has been overlooked the education, inheritance and development of the Chinese excellent traditional culture and Xinjiang regional culture.Some teenagers blindly accept western culture, which result their concept of values and way of life also gradually changed.They were attracted to western business, consumption and entertainment culture, taking western culture as fashion and standard, and being not interested to our own history, culture, art and language.The culture resources of the Chinese nation does not get enough attention and development, the cultural tradition and folk art of the Chinese nation get no inheritance and development, the result is only that the particularity of the national culture is submerged in the tide of cultural convergence, the vitality of the national culture is consumed in the ignored social environment, which lose their existing cultural essence.

\section{Neighboring Security Grounds}

The threats in the field of non-traditional security in Xinjiang region, its territory shareing a border with a number of countries, will be spreaded and influenced by the surrounding countries and regions. Therefore, Xinjiang region's non-traditional security threats in the neighboring security grounds can not be underestimated.These mainly include frontier security, multinational drug trade, 
cross-border ethnic and cross-border river problem and more.

\subsection{Frontier Security Problem}

Xinjiang region, from northeast to southwest, with the eight countries adjacent respectively such as Mongolia, Russia, Kazakstan, Tajikistan, Afghan, Pakistan and India, has more than 5600 kilometers boundary line.As the change of international and domestic situation, the non-traditional security factors affecting Xinjiang region border security are growing rapidly.The frontier security problem mainly includes four aspects: One is the disputable events of the national sovereignty.The basic characteristics of such events is directly related to the national sovereignty and territorial integrity, once these couldn't be disposed well, the national sovereignty and territorial integrity will suffer a loss.This type of events often occur at large scale and long sustain period, the two sides maintain a certain military presence in the region at ordinary times, and in the event of conflict with the use of more force and strong political sensitivity, the border territorial disputes, ethnic and religious issues, border security events and diplomatic struggle are intertwined, the situation being highly complex, once it couldn't be disposed well, it could trigger a large-scale armed conflict.The second is the political events of the border.It mainly refers to the terror, turbulence and riotous incident at border.These two types of events, with a definite political purpose and also with a clear targets, are a kind of political events in an organized, planned and premeditated way.Once such events have occurred, they will seriously damage the social order at the border areas, jeopardize the people's lives and property security, affect the good-neighborly and friendly relations with its neighboring countries. The third is the border security affairs.It mainly refers to the border public security(administration) and criminal cases, and most of these concerning the foreign affairs.These include border drug crimes, smuggling and illegal immigration events, interests disputes of the border inhabitant in two sides, border refugees affluence events, etc.The fourth is the border natural disaster events.Along the border region, the condition of physical geography is complex, and the natural disasters become more frequent.Due to the relatively backward natural and economic conditions and less permanent population, the ability to resist natural disasters is quite weak.Once it happened, it not only may cause economic losses to the people, also can cause the border political events concerning foreign affairs.

\subsection{Transnational Drug Trade Problem}

Since the 1980s, with the rise of the international drugs flowing and the spread of drug crimes, drug also expand in Xinjiang with a more rapid trend.Since the 199the 20th centurys, the two big drug sourcelands of "Golden Triangle", "Golden Crescent" has formed the situation of "attacking from both the east and the west, entrying from multipoint"to Xinjiang.Drug addicts in Xinjiang region increase rapidly, natives of Xinjiang drug trafficking are in common, the international drug trafficking begin to form taking Xinjiang as a channel and a consumption market, the drug situation in Xinjiang and the spread of AIDS(acquired immune deficiency syndrome) has entered a peak period soon."According to the statistics, there are 3000 drug addicts in this district in 1991, 2000 by 2000, by the end of 2005 the drug addicts had registered for 24625 people.Which was a 6.4 percent rise over the year 2000."In recent years, this data is still in a rising trend.Just for the "Golden Crescent", "in the past two years, the quantity to our country's entry drug harm has exceeded the Golden Triangle."More importantly, on the one hand, the drug crime has become the guise of the political attempts that the western hostile forces incite the masses, create chaos, "westernize","differentiate" our country, reflecting the political ambitions of "Xinjiang independence" in the drug problem; On the other hand, the transnational drug trade problems always have been an important way to raise money by the terrorist forces, and are closely linked with illegal immigration, smuggling, money laundering, and trafficking guns and weapons of mass destruction, which is likely to be another channel that the"East Turkistan" penetrate to our country, and become a new type of threat in the field of non-traditional security.

\subsection{The Transnational Nationality Problem}

What is called cross-border ethnic groups refers to the people living life in the border region across 
national borders due to the traditional settlements segmented by the modern national political territory.Uyghur, Kazakstan, Kyrgyz, Uzbekistan, Tadzhikistan and Russia rooted in Xinjiang belongs to cross-border ethnic groups.Xinjiang region is an area of that the cross-border ethnic groups are relatively complicated in China even all over the world, which also makes the non-traditional security issues in Xinjiang region present the complexity of the cross-border.The impact of cross-border ethnic groups in the field of non-traditional security mainly embodied in the following three aspects:First, due to the migration of the cross-border ethnic group, the impact can be an inducement affecting the state-to-state relations. Taking Kazak as an example, after the disintegration of the Soviet Union, Kazakstan once called Kazakh worldwide "return to the motherland".Outside China as kazakhstan kazakh most populous country, the country with the largest number of immigrants to kazakhstan, and the migration has become one of the big problems affecting the relations between the two countries.Secondly, weakening citizen consciousness and identity potentially threat the territorial sovereignty.With certain complexity in the citizens consciousness, national and ethnic identity, the cross-border ethnic groups are easy to put the overseas compatriots as their spiritual and material supporter, publicly declareing the national unique advantages and strength and raising the banner of the national unity to hope to build their own country with the compatriot together.In this sense, the cross-border ethnic issues are almost all related to the territorial sovereignty issue.The cross-border ethnic issues usually have the openly or secretly support of overseas kin or governments of their countries.Thirdly, they are easy to be used by anti-China forces, which may affect the ideology and the concept of values.Some foreign anti-China forces by means of radio, television and networks propagandize ethnic group disruption idea to our cross-border people, and with the so-called "human rights", national family planning, religious belief and other issues launch an attack to the Chinese government, trying to win popular support or to penetrate the ideology with the political purpose of spliting the country and undermining the national solidarity.

\subsection{The Cross-border River Problem}

As early as the 1977 the United Nations conference on water resources have been warned: "the next crisis after the oil crisis is the crisis of water". With the increasing ability of the human taking advantage of rivers, the contradiction of water resource utilization of cross-border rivers is comparatively sharpen, which become the non-traditional security threats affecting the peripheral relationship.In Xinjiang, Irtysh River, Ili River, Tarim River, and EMin River all are cross-border rivers, and have both the outflowing and inflowing river.Taking Ili River and Irtysh Riverthese as examples, they are two largest cross-border rivers in Xinjiang region, after exiting from here inflowing into the neighbors of Kazakstan.In recent years, with our country on the development and utilization of the two rivers, and even in some media there is the argument of "China water threat", which accuse China of excessive development of cross-border rivers, and think the overusing of the Ili River within the territory of China in Xinjiang as well as Irtysh River are bringing very adverse effects to Kazakstan located in the downstream of the river, the consequence of which could lead to ecological disaster.Kazakhstan also shows concern and criticism, "in the region of Balkhash Ozero injected by the river (Ili River) the water source currently has seriously overused, and China's excess water will cause the lake area is dry, subsequently will bring serious ecological disaster in this area."'China unilaterally expanding use of cross-border rivers can bring the following negative results to Kazakstan: In the Balkhash Ozero and Ethan lake area, the natural water balance and natural balance is broken;Climatic deterioration; Fishery loss; Agricultural harvests down; Pasture degeneration; The harmful material in the water increased, no longer qualifying for the standard of agricultural use and daily consumption."While the fact is that, due to historical reasons, the infrastructure construction on these two rivers has been slow, resulting in $75 \%$ throughflows outflowing abroad. The development and utilization of cross-border river has become a difficult topic of the non-traditional security threats in Xinjiang and the Central Asia. 


\section{Reference}

[1]Li Yeping \& Li Haiqing, Research on Ethnic Regional Issue in the Theater [M] Xi'an Army Academy, Mar. 2008

[2]An Xiaoping, Xi Guiping and Li Xinming, A Tentative Study on the Particularity of Non-traditional Security Threats in Xinjiang [J]. Journal of Tarim University, 2010 (3).

[2]Wu Chaoquan, Research on Military Operation Issue of Non-traditional Security [M]. PLA Publishing Press, Nov.2006

[3]Yu Xiaofeng, Pan Yihe, Wang Jiangli, Introduction to Non-traditional Security [M]. Zhejiang People's Publishing House, Jun. 2010.

[4]Liu Yuezhen, An Analysis of Non-traditional Security Challenges and Countermeasures in Xinjiang [J]. The Border Economy and Culture, 2009 (8).

[5]Gao Rudong, Song Dezhi. Advantages and Disadvantages of Answering Non-traditional Security Threats in Xinjiang Under the Perspective of National Cross-border [J]. Journal of Tarim University, 2011 (3)

[6]Xie Debo, Shang Zhen, Zhu Hao, Analasis of the Corps "Culture Frontier" Practice in Xinjiang Non-traditional Security Field [J]. Journal of Corps Party School, 2010 (4)

[7]Gao Yongjiu, The Issues and its Characteristics of Non-traditional Security in the Surrounding Areas in Xinjiang, China [J]. Journal of Xinjiang Social Science, 2005 (3)

[8]An Xiaoping, Xi Guiping and Li Xinming, A Tentative Study on the Particularity of Non-traditional Security Threats in Xinjiang [J]. Journal of Tarim University, 2010 (9).

[9]Liu Yuezhen, An Analysis of Non-traditional Security Challenges and Countermeasures in Xinjiang [J]. The Border Economy and Culture, 2009 (8).

[10]Shi Chunyan, The Focus of Xinjiang Nnational Work of Non-traditional Security in the New Century [J]. Journal of Changchun University, 2012 (1)

[11]Chen Chao, The Struggle Between Separatist and Anti-separatist, [M]. Nationalities Publishing House, Jul. 2009.

[12]Li Qi, Research on "East Turkistan" Separatist Forces [M]. China Social Sciences Press, Dec.2004

[13]Zheng Minhe, A Real Xinjiang [M]. People's Publishing House, Dec. 2009

[14]Mu Zhen, Ni Huifang, Social Stability and Development of the Frontier Minority Area [M]. China Social Sciences Press, Dec.1997

[15]Chen Lin. Research on the Chinese Frontier Governance [M]. Yunnan People's Publishing House, Jan. 2011.

[16]Zhu Qin, Harmonious Governance in the Frontier Minority Area: in the Framework of Emergency Management [M]. Yunnan People's Publishing House, October 2009.

[17]Yu Xiaofeng, Xu Lili \& Li Zhengyuan, An Introduction to the Frontier Security [M]. China Social Sciences Press, Aug. 2013.

[18]Wang Yizhou, China and Non-traditional Security [J]. International Economic Review, 2004 (6) 